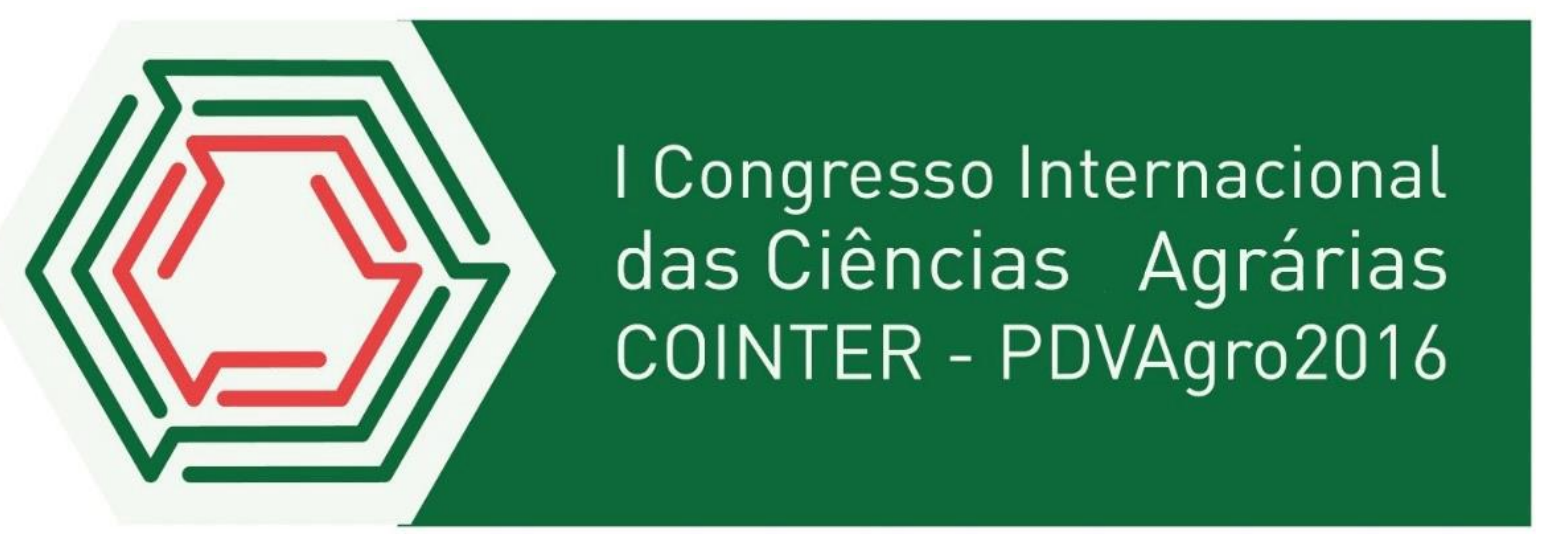

\title{
OFICINAS DE PRODUÇÃO DE PODCAST: CAPACITANDO AGENTES MULTIPLICADORES PARA APOIO AO CAMPESINATO
}

\author{
Apresentação: Comunicação Oral \\ Silvio Gleisson Bezerra ${ }^{1}$; Juliana da Costa Ramos ${ }^{2}$; Jorge Luiz Schirmer de Mattos ${ }^{3}$ \\ Francisco Roberto Caporal ${ }^{4}$
}

\begin{abstract}
Resumo
Tendo como pano de fundo o multifacetado cenário midiático, em constante mutação em virtude das inovações tecnológicas em curso, este artigo apresenta reflexões sobre os resultados da ferramenta oficina pedagógica para produção de conteúdos radiofônicos para a internet, partindo de quatro abordagens distintas e complementares: Educação, Comunicação Digital, Comunicação/Extensão Rural e Agroecologia. A Oficina de Produção de Podcast teve como lócus o estúdio-laboratório da Rádio Web Agroecologia (RWA), vinculada ao Núcleo de Agroecologia e Campesinato (NAC), localizado no campus da UFRPE, com o objetivo de capacitar agentes multiplicadores, tendo como participantes: professores, bolsistas e alunos de diversos cursos. Na Oficina foram capacitados agentes multiplicadores para comunicação voltada para o campesinato e povos tradicionais, usando o podcast como principal ferramenta de produção, registro de experiências e compartilhamento de saberes dos participantes. Analisamos neste trabalho os resultados quantitativos dos conteúdos produzidos e número de participantes contemplados pela iniciativa, bem como também as avaliações qualitativas, analisadas a partir da observação da interação dos participantes e colaboração no processo de criação dos conteúdos radiofônicos, utilizando as técnicas de produção de rádio a serviço da Comunicação/Extensão Rural. Neste sentido, este artigo apresenta possibilidades de construção de uma nova perspectiva de atuação de professores e estudantes, como agentes multiplicadores para apoio ao campesinato e povos tradicionais, apropriando-se das tecnologias digitais e da metodologia de produção radiofônica.
\end{abstract}

Palavras - chave: Comunicação, Internet, Rádio, Podcast, Extensão Rural.

\footnotetext{
1 Curso de Especialização em Docência e Gestão do Ensino Superior, Estácio Recife. E-mail: sgbson@gmail.com

2 Mestra em História Social da Cultura pela UFRPE. Email: julianadacostaramos@outlook.com

3 Professor de Extensão Rural. NAC/Departamento de Educação, UFRPE. E-mail: jsmattos@hotmail.com

4 Professor de Extensão Rural. NAC/Departamento de Educação, UFRPE. E-mail: caporalfr@gmail.com
} 


\title{
Introdução
}

A comunicação, ao longo dos últimos anos, vem agregando novas formas de produção e compartilhamento. A evolução da internet e o considerável aumento da acessibilidade às ferramentas tecnológicas transformam, a cada dia, o espectador-ouvinte-leitor passivo em sujeito ativo no processo comunicacional. As tecnologias de consumo e produção de conteúdo, presentes no universo on-line, têm contribuído para o surgimento de um novo perfil de produtor. Por isso, a atuação do e-produtor ${ }^{*}$, tem extrapolado os limites do campo profissional da Comunicação, constituído por um mercado de radiodifusão verticalizado e fundamentado na relação unilateral entre as empresas de mídia e o público consumidor.

Desse modo, discute-se o papel da internet neste cenário de mudanças de paradigmas na Comunicação, podendo ser analisada a partir de duas perspectivas fundamentais: a web como meio de transmissão que revolucionou outros veículos como a mídia impressa, a televisão e o rádio, agregando novas formas de produção de baixo custo (programas de edição de áudio e vídeo e equipamentos de gravação) e facilidade de distribuição através da web (rádio web e podcast); e como meio de convergência de várias linguagens ainda em processo de construção (MEDITSCH, 2001). Neste cenário, destaca-se o podcast como um dos principais suportes midiático, por sua facilidade de produção e distribuição. Segundo a definição de Barros e Menta (2004),

\begin{abstract}
Podcast é uma palavra que vem do laço criado entre Ipod - aparelho produzido pela Apple que reproduz mp3 e Broadcast (transmissão), podendo defini-lo como sendo um programa de rádio personalizado gravado nas extensões $\mathrm{mp} 3$, ogg ou mp4, que são formatos digitais que permitem armazenar músicas e arquivos de áudio em um espaço relativamente pequeno, podendo ser armazenados no computador e/ou disponibilizados na Internet, vinculado a um arquivo de informação (feed) que permite que se assine os programas recebendo as informações sem precisar ir ao site do produtor. (p.2)
\end{abstract}

Ademais, o podcast é resultado da hibridação da internet com o rádio convencional, agregando, também, possibilidades variadas de gêneros (jornalístico, publicitário, ficcional, educativo, musical, entre outros) e formatos (documentário, entrevista, reportagem, radionovela, etc.). Neste aspecto, através deste suporte, diversas formas de conteúdos podem ser revisitadas e atualizadas, tendo a internet como meio de compartilhamento e popularização de modalidades de discursos para diferentes atores sociais.

Neste sentido, o NAC/UFRPE vem desenvolvendo diversas iniciativas alinhadas com

\footnotetext{
* A referência mais próxima encontrada para conceituar o novo perfil de produtor foi a expressão prosumer - do inglês producer and consumer - criado pelo escritor Alvin Tofler em seu livro A Terceira Onda, publicado em 1980, para caracterizar a junção dos papéis de produtor e consumidor de informação.
} 
as inovações tecnológicas em curso, que chegaram também ao meio rural. Através de uma equipe multidisciplinar, iniciaram-se em 2013 as discussões com a comunidade acadêmica e entidades sociais, tendo como tema a criação de um projeto de Comunicação que promovesse a Agroecologia para além do espaço geográfico da UFRPE, servindo como ferramenta de empoderamento dos povos e comunidades tradicionais. Em seu documento de implantação está explicitada a linha de atuação RWA, destacando que a "rádio foi criada com uma missão e objetivos bem definidos, em consonância com os princípios da Agroecologia e pretende contribuir com a transição agroecológica em curso no estado, no país e no mundo" (CAPORAL e MATTOS, 2012). Esta diretriz fundamentou as etapas de consolidação da RWA, sendo a capacitação da equipe uma das mais importantes, servindo como embrião da Oficina de Produção de Podcast.

A partir de uma proposta pedagógica elaborada à luz das teorias de Freire (1983a) e Vieira e Volkind (2002a), a Oficina de Produção de Podcast tornou-se ferramenta de construção coletiva em sintonia com a popularização das recentes Tecnologias de Informação e Comunicação (TIC's). Tal iniciativa constituiu-se em instrumento de testagem e aprimoramento de novas metodologias de ensino-aprendizagem, que podem ser úteis às ações extensionistas de professores, estudantes e outros atores do meio rural, popularizando ferramentas como o podcast e a rádio web para diversos públicos. Após a capacitação de professores e bolsistas do NAC/UFRPE, outras Oficinas contaram com a participação de estudantes de várias áreas do conhecimento: Medicina Veterinária, Licenciatura em Ciências Agrícolas, Letras, Pedagogia e Comunicação Social com Habilitação em Rádio, TV e Internet, Jornalismo e Produção Fonográfica. O objetivo foi entender a percepção de professores e estudantes, enquanto agentes multiplicadores de conhecimentos e experiências, ao usarem esse suporte midiático nas atividades de Extensão Rural, engendrando uma práxis pedagógica para a Comunicação voltada para o campesinato e para os povos tradicionais.

Desse modo, este artigo tem como objetivo investigar os resultados destas Oficinas. Para isso, a abordagem está dividida em três partes: (1) a primeira, apresenta o aporte teórico que norteou este estudo, considerando-se três perspectivas complementares: as tecnologias digitais e as novas relações com o saber; (2) a segunda aborda a dialogicidade entre os atores através da Comunicação, caracterizada pela alternância dos papéis de emissores e receptores; e a (3) terceira avalia a Oficina como instrumento pedagógico neste recente cenário multimidiático. 
Inicia-se com uma análise do contexto convergente das mídias e dos usos dos suportes tecnológicos à luz das teorias de Levy (1993a) e Jenkins (2009a), trazendo também a perspectiva de Martín-Barbero (2006a, p. 51 -79) sobre o descentramento do saber; abordamse as considerações de Freire (1983b) acerca de uma práxis dialógica na Educação, tendo a Comunicação como ferramenta fundamental para o processo de ensino-aprendizagem; e, por fim, Vieira e Volkind (2002b) que apresentam conceitos fundamentais para a construção de propostas para oficinas pedagógicas. Na segunda parte, estão detalhadas as questões ligadas à metodologia fundamentada no levantamento bibliográfico, e na observação participante segundo a abordagem de Correia (2009 apud SPRADLEY, 1980 e LEININGER, 1991), através do modelo de observação, participação e reflexão, com a finalidade de compreender os comportamentos dos participantes antes e depois da Oficina. Por fim, a terceira parte apresenta uma avaliação crítica, refletindo-se sobre a metodologia empregada nas atividades propostas, além das impressões dos participantes acerca dos resultados gerados.

\section{Fundamentação teórica}

As sociedades vivem um momento de transformações socioculturais profundas, advindas da presença das tecnologias no cotidiano e dos seus usos massivos. Destarte, a Comunicação e a Educação, vêm passando por mudanças significativas nas formas de consumir, distribuir, compartilhar e, principalmente, de se produzir informação e conhecimento.

Logo, este é o cenário multifacetado de hibridações e metamorfoses midiáticas, que nasce com o surgimento de modalidades de interação que se consolidam rapidamente, alterando nossas percepções de mundo. Neste sentido, Levy (1993b) destaca que vivemos um momento ímpar, caracterizado pelas relações heterogêneas que se estabelecem com os novos e diferentes suportes midiáticos e que, através deles, estamos inventando e reinventando novos estilos de humanidades e desenvolvendo formas de interação mais horizontais. Similarmente, Jenkins (2009b) corrobora com este argumento, dando boas-vindas aos participantes deste momento histórico, que ele classifica como cultura da convergência (grifo nosso), caracterizado, também, pelo embate constante entre as novas mídias e as tradicionais, pelas transversalidades de conteúdos que dialogam com as diversas plataformas de compartilhamento, e pelas possibilidades de democratização da produção da informação. Ainda nesta linha de abordagem, Sabbatini (2011a) destaca que: 
Nesta convergência, a interatividade do meio digital permitiria que o tradicional receptor, elemento passivo do processo comunicacional, se transformasse em um receptor-emissor, capaz de produzir a mensagem, ao mesmo tempo em que a consumisse. Atuando em comunidades virtuais, cooperando livremente, estes receptores-emissores criariam uma inteligência coletiva, uma ação cognitiva em conjunto maior que as somas das partes (p. 42).

Assim, indivíduos comuns com acesso às novas ferramentas de informação presentes no ciberespaço, têm disputado espaços nos territórios comunicativos com as corporações midiáticas. Segundo Jenkins (2009c), em determinados momentos do mesmo lado, em outros em posições antagônicas, grandes produtores de conteúdo e consumidores-produtores individuais, alternam papéis num processo de constantes transformações e interações sociais, políticas, econômicas e culturais, tendo a Comunicação e suas recentes inovações tecnológicas como palco principal. São estes atores corporativos e alternativos que estão redefinindo os fluxos de produção, distribuição e consumo de conteúdo, alterando, também, o os meios de comunicação. Por isso,

Para uma definição de meios de comunicação, recorramos à historiadora Lisa Gitelman, que oferece um modelo de mídia que trabalha em dois níveis: no primeiro, um meio é uma tecnologia que permite a comunicação; no segundo, um meio é um conjunto de "protocolos associados ou práticas sociais e culturais que cresceram em torno dessa tecnologia". Sistemas de distribuição são apenas e simplesmente tecnologias; meios de comunicação são também sistemas culturais. Tecnologias de distribuição vêm e vão o tempo todo, mas os meios de comunicação persistem como camadas dentro de um estrato de entretenimento e informação cada vez mais complicado (GITELMAN apud JENKINS, 2009d p. 41).

De certo, as evoluções técnicas têm exercido importante papel nesta conjuntura comunicacional mais horizontalizada e mais acessível às grandes massas. Castro (1993 apud LEVY, 1993), aborda a questão das técnicas no nosso cotidiano, definindo-as como "pervarsivas", espalhando-se, infiltrando-se e difundindo-se, alterando nossa perspectiva em relação ao mundo. Neste sentido, Levy (1993c) reflete acerca da importância dos suportes de informação, como elementos condicionadores do fluxo do saber no ciberespaço. Enquanto ferramentas de compartilhamento, colaboram com o que Levy (1993d) chama de ecologia cognitiva das sociedades (grifo nosso), atuando como instrumentos de mobilização coletiva. Neste aspecto, fomenta-se um campo profícuo para o surgimento de diferentes espaços de produção do saber, para além das modalidades tradicionais de consumo de informação e da educação formal.

Fazendo um recorte para a Educação, o saber e suas novas configurações, MartínBarbero (2006b) problematiza a temática afirmando que:

Vivemos num ambiente de informação que recobre e mistura várias saberes e formas muito diversas de aprender, ao mesmo tempo em que se encontra fortemente 
descentrado em relação ao sistema educativo que ainda nos rege, organizado em torno da escola e do livro. Desde os mosteiros medievais até as escolas de hoje, o saber conservou esse duplo caráter de ser ao mesmo tempo centralizado e personificado em figuras sociais determinadas (p. 56).

Por outro lado, destaca-se a visão de Freire (1983bc) do quefazer educativo fundamentado na solidariedade e na reciprocidade entre os atores envolvidos no processo de aprendizagem. Nesta perspectiva, a construção de uma abordagem dialógica, livre e que valorize os saberes e valores dos agentes multiplicadores, fundamenta a construção de uma proposta de um quefazer comunicativo, ou seja, a Comunicação como principal ferramenta para a Educação e empoderamento de atores sociais das camadas populares. Trata-se de uma pedagogia que instrumentalize cidadãos, tornando-os partícipes, influindo, selecionando, opinando e, principalmente, produzindo seus próprios discursos. De modo que, estando esses atores inseridos no cenário da produção do saber a partir da sua realidade de mundo, se reconhecem e se veem como agentes de transformação, para si e para a sociedade, extrapolando os limites geográficos das suas localidades, tendo a internet como principal meio de compartilhamento de experiências e saberes.

Esse quefazer comunicativo, que privilegia a dialogicidade, como defende Freire (1983d), consolida-se através da Oficina enquanto instrumento pedagógico e multiplicador, que traz em sua essência as abordagens participativas e colaborativas na construção dos saberes compartilhados. Isto posto,

pode-se afirmar que se trata de uma forma de ensinar e aprender, mediante a realização de algo feito coletivamente. Salienta-se que oficina é uma modalidade de ação. Toda oficina necessita promover a investigação, a ação, a reflexão; combinar o trabalho individual e a tarefa socializada; garantir a unidade entre teoria e a prática (VIEIRA e VOLQUIND, 2002b p. 11).

Igualmente, é ressaltada, também, a importância para o compromisso pedagógico da Oficina, estabelecendo parâmetros norteadores em consonância com os pressupostos teóricos fundamentados no tripé pensar-sentir-agir, possibilitando o equilíbrio entre teoria e prática no desenvolvimento das atividades com o grupo de participantes. Assim,

A proposta de oficinas de ensino para ser séria gratificante e inovadora, necessita
criar um espaço para a vivência, reflexão e a construção de conhecimentos. Não é
somente um lugar para aprender fazendo; supõe, principalmente, o pensar, o sentir, o
intercâmbio de ideias, a problematização, o jogo, a investigação, a descoberta e a
cooperação (VIEIRA e VOLQUIND, 2002c p. 11).

Logo, a Oficina de Produção de Podcast para Agentes Multiplicadores para Apoio ao Campesinato, propõe um pensar que problematize o contexto de consumo da informação produzida pelos veículos de massa como o rádio, a televisão e a internet, e como estamos inseridos neste cenário multifacetado; um sentir que provoque inquietações e, principalmente, 
indique caminhos alternativos de criação de diferentes lugares de discursos, com a inserção e atuação de novos agentes produtores de informação e conhecimento; e, por fim, um agir que desmistifique e aproxime diferentes atores sociais das Tecnologias de Informação e Comunicação, engendrando novas práticas de produção de saberes e troca de experiências através destes suportes.

Mas como construir este quefazer comunicativo fundamentado no pensar-sentir-agir, no atual contexto de significativas e constantes mudanças tecnológicas no campo da Comunicação? De que modo é possível a partir de uma proposta pedagógica plural e dinâmica, estimulando o surgimento de agentes multiplicadores e produtores de Comunicação off-line e on-line, quebrando as barreiras econômicas, políticas, sociais e culturais que limitam o acesso por parte de alguns grupos sociais em áreas rurais e urbanas? Estas questões permeiam a abordagem fundamental desta pesquisa: pensar e refletir sobre um quefazer comunicativo que seja ferramenta libertadora, dinâmica e que respeite as especificidades de cada realidade social.

Neste contexto de convergência midiática, caracterizado pela presença ostensiva das TIC's, surgiu a Oficina de Produção de Podcast com a proposta de servir como ferramenta de inclusão digital e de multiplicação de conhecimentos, acerca dos processos da comunicação digital no contexto da Agroecologia. Inserem-se nesta classificação as duas principais mídias sonoras, usadas como ferramentas de compartilhamento de experiências e difusão de conhecimentos agroecológicos, que serviram como referências para a construção de uma proposta de aprendizado e apropriação dos seus respectivos usos: o podcast e a rádio web. Desse modo, a rádio web é um canal possível de veiculação em fluxo de conteúdos sonoros, sendo mais uma possibilidade de difusão e compartilhamento do podcast. Portanto, destacamos as distinções, inter-relações e complementaridades entre estas ferramentas, buscando-se construir uma abordagem mais ampla acerca da produção de conteúdo sonoro na internet. O podcast e a rádio web são suportes comunicacionais convergentes em virtude de suas características essencialmente híbridas, agregando diversas linguagens (imagens, áudio, vídeo, etc.), e transversais, por circularem em diversos espaços multimidiáticos. Com diversas possibilidades de utilização, complementam-se estreitamente no ciberespaço, servindo como tecnologias digitais que podem ser usados para diversos fins e nas mais variadas áreas do conhecimento. 
utilizar esses recursos em ambientes virtuais de aprendizagem, favorecendo uma inteligência colectiva no domínio educativo, e produzindo uma cibercultura na sociedade da informação (TEIXEIRA e SILVA, 2010 p. 253).

Portanto, refletimos sobre a apropriação dos conceitos das mídias sonoras no ciberespaço - o podcast e a rádio web - o domínio das técnicas de produção radiofônicas, adaptadas às realidades dos participantes de cada oficina, para além das especificidades do exercício da profissão de comunicador - jornalistas e radialistas -, bem como investigar o processo de construção de um novo produtor de informação na web - o e-produtor utilizando novas formas de capacitação de agentes multiplicadores para uma comunicação essencialmente popular, dialógica e horizontal com a sociedade.

\section{Metodologia}

Para investigar os resultados da Oficina, trabalhamos com as ferramentas da Observação Participante como principais instrumentos de avaliação, através do modelo pautado na observação, participação e reflexão destacado por Correia (2009 apud SPRADLEY, 1980 e LEININGER, 1991). Neste aspecto, foram consideradas as ações dos atores inseridos no contexto de aprendizado das práticas de produção radiofônicas, através do nível de envolvimento nas atividades sugeridas pelo facilitador, tendo como proposta pedagógica fundamental, estimular em cada participante uma mudança de atitude, saindo da condição de receptor para o papel de produtor de conteúdos.

A capacitação teve duração total de 10 (dez) horas, divididas em dois períodos matutinos e subsequentes, e intervalos de 15 (minutos) entre as atividades de discussão e produção. Servindo como embrião para a proposta de capacitar agentes multiplicadores, esta primeira iniciativa além do caráter técnico, como ferramenta instrumentalizadora para o aprendizado dos processos operacionais da RWA e da produção dos podcasts, buscou promover a discussão acerca dos conceitos da Comunicação, partindo das experiências dos participantes com as mídias sonoras (rádio tradicional, rádio web e podcast).

A Oficina foi dividida em quatro momentos específicos:

Primeiro momento - Dinâmica de apresentação com perguntas dirigidas: Como você escuta rádio? b) Você sabe o que é podcast? c) Você escuta podcast e rádio web?

A cada apresentação individual e experiência compartilhada com o grande grupo, apresentamos a evolução tecnológica da mídia ao longo dos últimos anos, e as relações estabelecidas com o veículo no cotidiano, aproximando cada participante do papel de produtor 
no atual contexto de convergência do rádio.

Segundo momento - Explanação de temáticas com retomada das colocações dos participantes, dentre as quais destacamos evolução das mídias sonoras, as mudanças de comportamento dos ouvintes, os conceitos de rádio web e podcast, e os usos socioculturais destes suportes no ciberespaço nos espaços urbanos e rurais. A proposta deste momento foi apresentar os conceitos fundamentais dos suportes e debater acerca das possibilidades de utilização para além da perspectiva operacional com o aprendizado técnico das ferramentas. Neste sentido, abordamos a questão do domínio das ferramentas inseridas na realidade dos participantes, refletindo sobre o como fazer e, principalmente, o porquê fazer.

Terceiro momento - Elaboração de programa de rádio usando o podcast como suporte Como ponto alto da Oficina foi proposto como desafio para o grupo, a produção de podcasts formatados como programas de rádio, partindo da construção coletiva da elaboração do conceito do conteúdo e formato. Desse modo, a atividade foi fundamentada no encadeamento de tarefas acompanhadas da apresentação dos conceitos de cada etapa de produção radiofônica, tais como: planejamento e pré-produção do podcast, elaboração de roteiro, locução, gravação de áudio e edição.

Quarto momento - Audição e avaliação

A audição constituiu-se em momento de avaliação coletiva dos programas produzidos, com a valorização das experiências dos participantes enquanto produtores de conteúdos. Neste aspecto, com o fechamento das atividades buscou-se verificar os seguintes indicadores: (1) se cada participante, apropriando-se dos conceitos teóricos e operacionais básicos, produziu um podcast; (2) se esse domínio teórico e técnico representou uma mudança de atitude, estimulando o participante a sair da condição de receptor para a posição de e-produtor.

Destacam-se os seguintes recursos didáticos usados durante a execução das atividades: a) slides com imagens, como suportes para as explanações; b) audição de diferentes rádios web e podcasts para construção de referências sonoras, buscando aproximar os participantes com a linguagem radiofônica; c) manuseio de computadores desktop com acesso à internet, para pesquisa de conteúdo e redação de roteiro on-line, com edição em tempo real, usando a ferramenta Google Docs como plataforma de produção colaborativa entre as equipes de produção e o facilitador; d) equipamentos de áudio como microfones, placa de áudio e fones de ouvido, para as atividades de gravação e edição dos podcasts. 


\section{Resultados e discussão}

A primeira Oficina de Produção de Podcast foi realizada em setembro de 2014 nas dependências da NAC/UFRPE, e contou com 10 participantes, incluindo professores e estagiários da Rádio Web Agroecologia, oriundos de diversos cursos de graduação, tais como: Engenharia Florestal, Licenciatura em Letras, Medicina Veterinária, Licenciatura em Ciências Agrícolas, Comunicação Social com Habilitação em Radialismo e Jornalismo e Produção Fonográfica.

Como resultado, foram produzidos três conteúdos sonoros com os temas: Saúde e Feiras Agroecológicas, Água e Agroecologia e um Boletim Informativo sobre Agroecologia, todos com duração média de três minutos e veiculados na programação da Rádio Web Agroecologia.

Além disso, em 2015, já com a RWA em pleno funcionamento, foram realizadas mais três Oficinas. Nestas edições, alguns participantes da primeira Oficina atuaram como facilitadores e co-facilitadores, colocando em prática a proposta inicial de multiplicação do conhecimento para a Comunicação/Extensão Rural. A ferramenta também foi utilizada como atividade complementar em disciplinas de Extensão Rural ministradas em vários cursos da UFRPE, como Licenciatura em Ciências Agrícolas, Medicina Veterinária, Agronomia, Engenharia Florestal, entre outros.

Em 2016, foram mais três Oficinas oferecidas, sendo a primeira voltada para capacitação da equipe para elaboração de uma nova grade de programação da RWA, e a segunda para estudantes de Engenharia Florestal com foco na utilização do podcast, como ferramenta pedagógica para Educação Ambiental para os futuros profissionais desta área. Por fim, a terceira Oficina teve como recorte a produção de podcast com ênfase em radionovela, e capacitou agentes multiplicadores - estudantes bolsistas da UFRPE e do ensino médio participantes do projeto Tecendo Histórias a partir do lazer e da Extensão Rural, destinada às mulheres da comunidade Vila Nova Tatuoca, localizada no município do Cabo de Santo Agostinho em Pernambuco.

Em pouco mais de dois anos, foram capacitados 50 participantes, entre estudantes e professores da UFRPE, bolsistas de vários projetos de extensão e representantes de comunidades tradicionais. Com isso, verificou-se uma participação significativa nas atividades propostas pelos facilitadores, estimulando a construção do conhecimento da produção da comunicação, a partir das experiências dos próprios participantes. 
Considerando-se estas questões, as avaliações dos participantes apontaram para a desmistificação relacionada ao uso das tecnologias de produção radiofônica (técnicas de gravação, edição de áudio, etc.), como ferramentas acessíveis e fáceis de serem manejadas; a possibilidade de uso das técnicas de produção radiofônica de um programa de rádio, aplicada às produções de baixo custo; o uso pedagógico do podcast para diversas áreas do conhecimento; e, finalmente, a transição dos participantes-ouvintes para participantesprodutores, com a tomada de consciência atenta para as possibilidades de produção e compartilhamento de saberes e experiências através das recentes Tecnologias de Informação e Comunicação disponíveis.

\section{Conclusões}

$\mathrm{O}$ acesso às tecnologias digitais, longe de ser um bem adquirido por poucos, deve essencialmente, ser um direito assegurado para todos. Excluir grupos, comunidades e povos tradicionais deste processo é, antes de tudo, um ato que atenta contra as liberdades individuais que reverberam em esferas sociais mais amplas. Neste aspecto, através da promoção e popularização de ferramentas pedagógicas como a oficina de capacitação, é possível desencadear um processo gradativo de inserção no âmbito da Comunicação para diferentes atores sociais, postos à margem pelos grandes veículos de mídia. Por isso, urge criarem-se alternativas possíveis e viáveis para a construção coletiva do conhecimento, antes de tudo, contextualizadas e inseridas nas realidades sociais, respeitando e utilizando as diferenças e especificidades dos grupos como ponto de partida.

Por isso, a Oficina de Produção de Podcast é um objeto de estudo ainda pouco explorado, mas com perspectivas bastante promissoras. Fato é, que o acesso às técnicas de produção de rádio voltada para o podcast, enquanto ferramenta de Comunicação/Extensão Rural aponta para a necessidade da construção de novas possibilidades de atuação, cujos papéis dos agentes multiplicadores passariam a adquirir também novos significados, na medida em que, apropriando-se da comunicação digital, promovem a transição agroecológica e divulgam os fundamentos e princípios da Agroecologia.

\section{Referências}

BARROS, G.C., MENTA, E. Podcast: produções de áudio para educação de forma crítica, criativa e cidadã. EPITC - Revista de Economía Politíca de las Tecnologías de la Informacíon y Comunicación, vol. IX, n. 1 ene. - abr./2007. 
CAPORAL, F.R., MATTOS, J.L.S. Rádio Web Agroecologia: as outras vozes do rádio. Documento oficial, 2012.

CORREIA, M.C.B. A observação participante enquanto técnica de investigação. Pensar Enfermagem. Vol. 13, N 2, $2^{\circ}$ Semestre, 2009.

FREIRE, P. Extensão ou comunicação?.Rio de Janeiro. $16^{\text {a }}$ Edição. Editora: Paz e Terra. 2013.

JENKINS, H. Cultura da convergência: a colisão entre os velhos e novos meios de comunicação; tradução Susana Alexandria. - 2a ed. - São Paulo: Aleph, 2009.

LÉVY, P. As tecnologias da inteligência: o futuro do pensamento na era da informática. Tradução de Carlos Irineu da Costa. - Rio de Janeiro: Ed. 34, 1993. 208 p.

MEDITSCH, Eduardo. O ensino do radiojornalismo em tempos de internet. XXIV Congresso Brasileiro da Comunicação - Campo Grande /MS - setembro 2001

MORAES, D. (org.). Sociedade midiatizada. Traduções de Carlos Frederico Moura da Silva, Maria Inês Coimbra Guedes, Lucio Pimentel. - Rio de Janeiro: Mauad, 2006.

TEIXEIRA, M.M., SILVA, B.D. Rádio Web \& podcast: conceitos e aplicações no ciberespaçoeducativo. ACTAS ICONO 14, 2010, No A4, pp. 253-261.

SABBATINI, M.A. Folkcomunicação na era da convergência midiática digital: da folksonomia às narrativas folkmidiáticas transmídia. Razón y Palabra, v. 77A, p. 8, 2011.

VIEIRA, Elaine; VOLQUIND, Lea. Oficinas de ensino: O quê? Por quê? Como? $4^{\circ}$ Ed. Porto Alegre. Ed. EDIPUCRS, 2002. 